\title{
Humeral Chondral Defect and Labral Tear Associated with Paraglenoid Labral Cyst: A Case Report
}

\author{
Berhan Pirimoglu Hayri Ogul Mecit Kantarci \\ Department of Radiology, Medical Faculty, Ataturk University, Erzurum, Turkey
}

\author{
Key Words \\ Paraglenoid labral cyst · 3D VIBE MR arthrography \\ sequence $\cdot$ Labral tear . Chondral defect
}

\begin{abstract}
Objective: To report an unusual combination of paraglenoid labral cyst and labral tear with chondral defect of the humeral head. Clinical Presentation and Intervention: A 34-year-old man presented with right shoulder pain. Conventional MR imaging showed paraglenoid labral cyst. MR arthrography revealed a humeral chondral defect and labral tear associated with paraglenoid labral cyst, and a defect of the posterior inferior labrum extending to the superior labrum and humeral chondral defect. The patient underwent arthroscopic surgery. Conclusion: This case showed the importance of MR arthrography in a case that involved an unusual combination of paraglenoid labral cyst and labral tear with chondral defect.

○ 2016 S. Karger AG, Basel
\end{abstract}

\section{Introduction}

Paraglenoid labral cysts (PLCs) of the shoulder can cause chronic shoulder pain and they most frequently occur along the posterior, superior and anterior aspects of the glenohumeral joint [1]. There is clustered appearance of these cysts in combination with superior labral tear from anterior to posterior (SLAP) lesions, which can lead to cysts [2,3]. Two particular pathologies of SLAP lesions and labral cysts, in particular SLAP II lesions, have been reported [3-6]. Herein, we present a case of posterior PLC, massive labral tear and chondral defect of the humeral head.

\section{Case Report}

A 34-year-old, right-hand-dominant, otherwise healthy man was admitted for evaluation of mild right shoulder pain. His history revealed mild shoulder pain that increased with lifting objects and reaching out activities. He did not participate in any sports activity and had no limitation of any function of the shoulder. Neurovascular examination showed that the right upper extremity was intact. A stability examination of the shoulder revealed no sulcus sign and +1 anterior and posterior translation of the humeral head without apprehension. Based on his examination and a concern for occult labral pathology, radiographs were made and an MR imaging scan of the right shoulder was done. MR arthrography and conventional MR imaging examination were performed with a 3-T MR scanner (Magnetom Skyra, Siemens Healthcare, Forchheim, Germany).

The axial proton density and T1-weighted MR imaging of the shoulder showed a fluid-filled PLC that originated at the posterior portion of the glenoid bone that extended to the posterior superior labrum, including heterogeneous signal intensities within the cyst (fig. 1a, b). The cyst was approximately $20 \times 35 \times 45 \mathrm{~mm}$. Additionally, pathologic high signal changes of the posterior superior labrum were detected on the routine MR images. On MR arthrogra-

\begin{tabular}{ll}
\hline KARGER & $\begin{array}{l}\text { ( ) 2016 S. Karger AG, Basel } \\
1011-7571 / 16 / 0255-0488 \$ 39.50 / 0 \quad \text { Karger }\end{array}$ \\
$\begin{array}{l}\text { E-Mail karger@karger.com } \\
\text { www.karger.com/mpp }\end{array}$ & $\begin{array}{l}\text { This is an Open Access article licensed under the terms of the } \\
\text { Creative Commons Attribution-NonCommercial 3.0 Un- } \\
\text { ported license (CC BY-NC) (www.karger.com/OA-license), } \\
\text { applicable to the online version of the article only. Distribu- } \\
\text { tion permitted for non-commercial purposes only. }\end{array}$
\end{tabular}

Hayri Ogul, MD

Department of Radiology, Medical Faculty, Ataturk University

Kazım Karabekir Mah., Terminal Cad., Site Polat Apt. B Blok, Kat 1, No 2

TR-25240 Erzurum (Turkey)

E-Maildrhogul@gmail.com 
Fig. 1. Axial proton density-weighted (a) and T1-weighted (b) MR images showing unilocular PLC (asterisk) in spinoglenoid notch. Oblique sagittal (c) and oblique coronal (d) fat-saturated 3D VIBE MR arthrographic images showing massive tear of the posterior glenoid labrum (dotted arrows). The oblique coronal fat-saturated 3D VIBE MR arthrographic image also shows a SLAP lesion (dotted arrow) and humeral chondral defect (arrow). e Axial fat-suppressed T1-weighted MR arthrographic image shows contrast material extravasation inside uniloculated cyst. $f$ Oblique sagittal fat-saturated 3D VIBE MR arthrographic image shows a 6-mm humeral chondral defect (arrow).
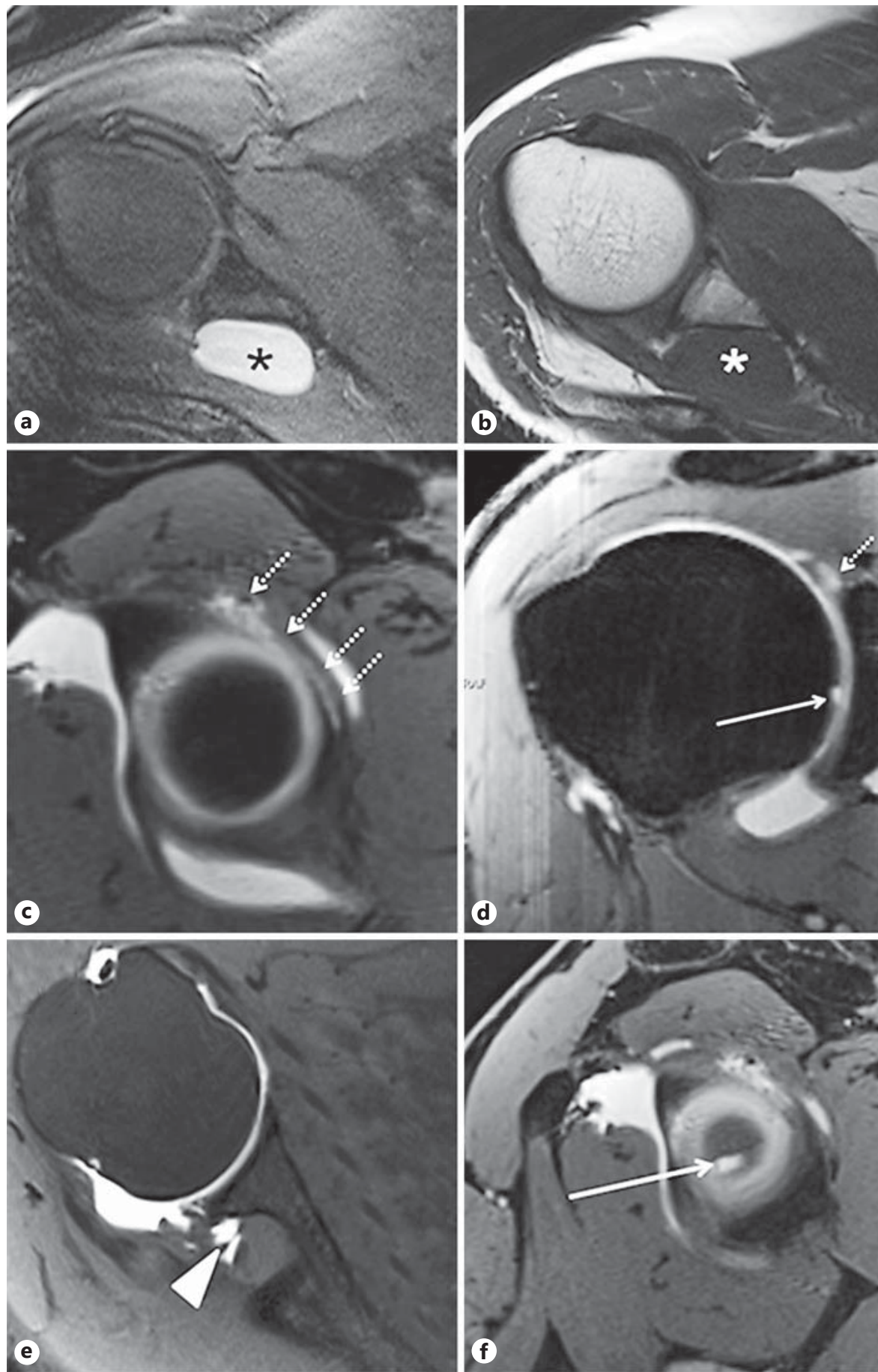

phy, there was defect of the posterior inferior labrum. The defect was extended to the superior labrum and associated with a SLAP lesion (fig. 1c, d). The contrast agent extravasated from the labral defects to the posterior PLC (fig. 1e). In addition to these arthrographic findings, three-dimensional volumetric interpolated breath-held examination (VIBE) as a sequence on MR angiography revealed the chondral defect in a region of about $6 \mathrm{~mm}$ at the inferior portion of the humeral head sequence (fig. 1f). The patient was referred to the arthroscopy unit for treatment and to confirm our MR arthrography findings. Surgical therapy involved arthroscopic repair of the labral tear, as well as arthroscopic debridement of the humeral chondral defect and drainage of the cyst. The patient was recalled for after 6 months. 


\section{Discussion}

In this case report, there was an association between the posterior PLC with glenohumeral joint spacing and the massive posterior labral tear on the MR arthrography images. The labral tear extended to the superior labrum. PLCs could be clinically important because most PLCs are associated with labral tears, and entrapment neuropathy of the suprascapular nerve from a cyst might occur in the suprascapular notch or spinoglenoid notch [4-6]. PLCs are often incidentally discovered on routine MR imaging of the shoulder, but the PLC and the association with labral tears are not always revealed on routine MR imaging $[6,7]$. MR arthrography plays a very important role in detecting labral cysts and accompanying lesions such as rotator cuff disease: SLAP lesions, impingement syndrome and occult instability $[1,6-8]$. In our study, the association of PLC with labral tear (SLAP type II) was previously confirmed and in addition, our patient also had the chondral defect at the inferior portion of the humeral head. Tung et al. [6] reported that labral tears were identified with $59 \%$ of paralabralcysts on routine MR imaging, but MR arthrography revealed labral tears in all the patients. Tirman et al. [5] found that 11 of 20 patients (55\%) with paralabral cysts had retrospective evidence of labral tears on routine MR imaging. In another study, Moore et al. [7] showed superior labral tears on arthroscopy in 10 of 11 patients with PLC and suprascapular nerve entrapment. Similar to previous studies, Tung et al. [6] also demonstrated 15 of 17 patients with PLCs on MR imaging had labral tears at arthroscopy [6].

When labral cysts of the shoulder present without any specific symptoms, clinicians have often empirically pursued a treatment strategy of rest and activity modification to address these symptoms. However, nonoperative management of such symptomatic SLAP lesions with pathologic paralabral cysts has not been successful in achieving long-term pain relief or consistent restoration of shoulder function [9]. Cyst aspiration may result in temporary relief of symptoms, but an untreated labral tear should be suspected if cysts recur [6].

\section{Conclusion}

This case shows the importance of MR arthrography in a case involving an unusual combination of PLC and labral tear with chondral defect. Hence, radiologists should pay more attention when making a diagnosis of labral tear and associated lesions.

\section{References}

1 Ji JH, Shafi M, Lee YS, et al: Inferior paralabral ganglion cyst of the shoulder with labral tear - a rare cause of shoulder pain. Orthop Traumatol Surg Res 2012;98:193-198.

2 Kessler MA, Stoffel K, Oswald A, et al: The SLAP lesion as a reason for glenolabral cysts: a report of five cases and review of the literature. Arch Orthop Trauma Surg 2007;127: 287-292.

3 Bedi A, Dodson C, Altchek DW: Symptomatic SLAP tear and paralabral cyst in a pediatric athlete. J Bone Joint Surg Am 2010;92: 721-725.
Steiner E, Steinbach L, Schnarkowski P, et al: Ganglia and cysts around joints. Radiol Clin North Am 1996;34:395-425.

5 Tirman P, Feller J, Janzen D, et al: Association of glenoid labral cysts with labral tears and glenohumeral instability: radiologic findings and clinical significance. Radiology 1994;190: 653-658.

-6 Tung GA, Entzian D, Stern JB, et al: MR Imaging and MR arthrography of paraglenoid labral cysts. AJR Am J Roentgenol 2000;174: 1707-1715.
Moore T, Fritts H, Quick D, et al: Suprascapular nerve entrapment caused by supraglenoid cyst compression. J Shoulder Elbow Surg 1997;6:455-462.

$>8$ Abboud JA, Silverberg D, Glaser DL, et al: Arthroscopy effectively treats ganglion cysts of the shoulder. Clin Orthop Relat Res 2006;444: 129-133.

$\checkmark 9$ Chen AL, Ong BC, Rose DJ: Arthroscopic management of spinoglenoid cysts associated with SLAP lesions and suprascapular neuropathy. Arthroscopy 2003;19:15-21. 